\title{
Construcción de conocimiento biomédico y políticas de salud: Síndrome Urémico Hemolítico y Fibromialgia
}

\author{
Biomedical knowledge and health policies: \\ Hemolytic Uremic Syndrome and Fibromyalgia
}

Marcela Beatriz Belardo ${ }^{1}$

Kenneth Rochel de Camargo Júnior ${ }^{1}$

${ }^{1}$ Departamento de Planejamento e Administração em Saúde, Instituto de Medicina Social, Centro Biomédico, Universidade do Estado do Rio de Janeiro. R. S. Fco. Xavier 524/7\%/Bl. D, Maracanã. 20559-900 Rio de Janeiro RJ Brasil marcelabelardo@ yahoo.com.ar

\begin{abstract}
The article deals with the construction of knowledge about diseases. The general objective is to analyze the process of constructing scientific knowledge of two diseases in comparative perspective: Hemolytic Uremic Syndrome and Fibromyalgia. The work reflects on the construction of biomedical knowledge and health policies, specifically how scientific knowledge impacts on the design of policies. Our research strategy was based on the analysis of scientific literature, health programs and bills of Argentina. The analysis was based on the axial model of diagnostic categories (semiological, morphological, explanatory and epidemiological) developed by Camargo Jr in order to detect how the distinctive features of biomedical sphere is translated into the political sphere. The investigation showed that the hierarchy given to each axis when a disease is defined at the moment of designing health policies is curcial. It also revealed that when biomedicine can not define the disease, based on their clinical and epidemiological reasoning, the roles are reversed. Then it is politics that recognizes the disease and gives the legitimacy that patients need.

Key words Scientific knowledge, Health policies, Diagnostic category, Hemolytic uremic syndrome, Fibromyalgia.
\end{abstract}

Resumen El trabajo tiene puesto su foco de atención en el proceso de construcción de conocimientos sobre enfermedades. El objetivo general es analizar ese proceso a partir de dos enfermedades en clave comparada: el Síndrome Urémico Hemolítico y la fibromialgia. Se reflexiona sobre cómo la construcción de conocimientos biomédicos modela el diseño de las políticas de salud. Nuestra estrategia de investigación se basó en el análisis de la literatura científica y de los programas de salud y proyectos de ley de Argentina. El análisis se basó en el modelo axial de categorías diagnósticas (semiológicas, morfológicas, explicativas y epidemiológicas) desarrollado por Camargo Jr. con el fin de detectar cómo se traducen los rasgos propios de la esfera biomédica en la esfera política. La investigación demostró que es decisiva la jerarquía otorgada a cada eje de definición de categoría diagnóstica al momento de diseñar una política de salud y reveló que cuando el campo biomédico no logra definir a la enfermedad en función de su raciocinio clínico-epidemiológico se invierten los roles entre la biomedicina y la política. Entonces es la política la que reconoce a la enfermedad otorgando esa legitimidad que los pacientes necesitan. Palabras clave Conocimiento científico, Políticas de salud, Categoría diagnóstica, Sindrome Urémico Hemolítico, Fibromialgia 


\section{Introducción}

El Síndrome Urémico Hemolítico (SUH) es una enfermedad infecciosa que afecta principalmente a niños menores de cinco años de edad. La enfermedad es causada por una bacteria (EscherichiaColi productor de toxina Shiga) que en Argentina se encuentra ampliamente diseminada en el ganado vacuno. La principal vía de transmisión de este tipo de bacterias son los alimentos y aguas contaminadas ${ }^{1}$. La enfermedad afecta el normal funcionamiento del riñón por lo que una vez superada la etapa aguda, los pacientes frecuentemente necesitan de un trasplante ${ }^{2}$. La enfermedad no tiene un tratamiento específico ni tampoco existen vacunas.

La fibromialgia es una entidad diagnosticada mayoritariamente a mujeres de entre 20 y 50 años. Es considerada un síndrome que causa una serie de síntomas como dolores musculares profundos, punzantes o ardientes que se propagan por todo el cuerpo, fatiga y cansancio y estado de ánimo deprimido junto con trastornos del sueño. Las causas de esta enfermedad son aún desconocidas y se presume que los desencadenantes pueden abarcar traumas físicos o emocionales, una respuesta anormal al dolor, infecciones como virus -aunque no se han identificado- o una predisposición genética. El tratamiento consta de diversas estrategias para aliviar el dolor y los otros síntomas (fisioterapia, medicamentos, asistencia psicológica $)^{3}$.

Ambas entidades mórbidas fueron "descubiertas" por la medicina durante la segunda mitad del siglo XX por lo que las respuestas de la práctica clínica y sus terapéuticas y las políticas de salud son de relativa reciente implementación. El objetivo de este artículo es comprender cómo las maneras de definir y de clasificar de las ciencias biomédicas influyen en los modos de abordar e intervenir sobre las enfermedades desde la salud pública. Es decir, el artículo no pretende discutir las causas de estas enfermedades o si los conocimientos producidos son veraces o si las terapéuticas son eficaces sino reflexionar, desde una perspectiva anti-esencialista de construcción de conocimientos, cómo el proceso de construcción de conocimiento biomédico modela el diseño de las políticas de salud.

El análisis sobre la construcción de conocimientos científicos será abordado a partir de un esquema teórico de descripción de creación de enfermedades elaborado por Camargo Júnior ${ }^{4}$. Este esquema sostiene que para la medicina existe una especie de "teoría de las enfermedades" que se manifiesta de forma implícita, o sea, una especie de "doctrina no-doctrinaria" que se lee entrelíneas. Es decir, para la clínica las enfermedades son cosas, de existencia concreta, fija e inmutable, de lugar para lugar, de persona a persona expresadas en un conjunto de síntomas y signos, que son manifestaciones de lesiones, que deben buscarse en el interior del organismo y corregirlas por algún tipo de intervención concreta. Esta "teoría de las enfermedades" fue construyéndose desde el nacimiento de la clínica en el siglo XVIII a partir de un acervo de ejemplos compartidos por médicos durante su aprendizaje y práctica profesional, constituyendo así el punto nodal de su saber y su práctica ${ }^{4}$. Este saber utiliza información de carácter científico, creando hipótesis/ abducciones que, articuladas a un razonamiento inductivo/deductivo, avanza en la elaboración de un diagnóstico ${ }^{6}$. Es así como desde el surgimiento de la racionalidad médica moderna se viene consolidando un proyecto de situar el saber y la práctica médica dentro del modelo de las ciencias naturales. Es decir, el objeto de la medicina se naturaliza, atravesando un proceso de objetivación que excluye la subjetividad de los pacientes. Los síntomas subjetivos no son tenidos en cuenta, más aún, no se sabe o mejor dicho no entra dentro de esta lógica de cómo "dar cuenta" de ellos?.

El estudio emplea la metodología de estudio de caso en perspectiva comparada. Para tal fin se seleccionó al SUH porque presenta una típica y completa descripción de los cuatro ejes (semiológico, morfológico, explicativo y epidemiológico) a partir de la cual la medicina clasifica y define una categoría diagnostica. Como caso contrapuesto se incluyó a la fibromialgia, una enfermedad de difícil clasificación para la ciencia biomédica, por lo que este contraste nos pareció significativo siendo el propósito comparativo la búsqueda de regularidades, semejanzas y/o diferencias.

En primer lugar se presenta el enfoque teórico-conceptual de los procesos de construcción de categorías diagnósticas por parte de la clínica procurando comprender a estas enfermedades en tanto ejemplos diagnósticos de la historia reciente de la medicina. Se incluye un esquema descriptivo que corresponde a las respuestas dadas por la salud pública. En segundo lugar, se discute el impacto de las construcciones de las categorías diagnósticas del SUH y la fibromialgia en el diseño de políticas de salud específicas para Argentina. Finalmente, se presentan las conclusiones relacionadas con nuestros casos de estudio, que constituyen nuestros analizadores para el tema 
escogido. A partir de ellos consideramos que es posible cierto grado de extrapolación para el análisis de casos similares. Es decir, que a partir de ellos es posible la extrapolación para el análisis de casos similares.

\section{Clínica, epidemiología y políticas de salud}

Para tener una definición completa de una enfermedad, o sea para arribar a una definición de categorías diagnósticas tal como lo hizo y continúa haciendo la clínica, reflexionamos a partir de cuatro ejes que se sucedieron desde el siglo XVIII con el nacimiento de la clínica hasta la actualidad. Si bien estos ejes de definición de categorías diagnósticas son sucesivos no implica que el último eje en términos temporales remplace al anterior.

El primer eje es el de la clínica propiamente dicha, donde las enfermedades son vistas como constelaciones de señales y síntomas, formando gestalts semiológicos. Este es el eje de la lectura del caso, que avanza en dos direcciones en simultaneo: la individualización, recorriendo un método indiciario para recortar un gestalt semiológico especifico, al mismo tiempo que hay un movimiento de generalización, localizando el caso individual en un inventario de enfermedades (un mapa nosológico, hoy representado por la clasificación contenida en el Código Internacional de Enfermedades). Es en esta última dirección que la clínica se asemeja a la epidemiología. Este eje inició su desarrollo en el siglo XVIII.

El segundo eje se basa en la descripción de lesiones características, patognómicas, terreno característico de la anatomía-patológica. El concepto de lesión sufre modificaciones básicamente en términos de su alcance, acompañado con el movimiento general de las disciplinas biológicas en dirección al microscopio. Contemporáneamente se exponen lesiones a nivel molecular. La mayor parte de la parafernalia laboratorial utilizada para la realización de los llamados exámenes complementarios estaría incluida en este eje, ya que tales exámenes se dirigen básicamente a evidenciar lesiones, la excepción estaría en los métodos que producen los grandes números que pueden figurar en el en el eje epidemiológico, sin caracterizar la lesión propiamente dicha. Históricamente este eje se consolida en un período que va de finales del siglo XVIII a los primeros años del siglo XIX.

El tercer eje corresponde a la caracterización de enfermedades como proceso, conteniendo una o más causas y una historia natural. Este eje es el de la fisiopatología, la experimentación en ani- males con la inducción de enfermedades artificiales. Aquí el saber médico se aproxima más al de las ciencias "duras" en el dominio de lo biológico. Este eje empieza a desarrollarse desde la segunda mitad del siglo XIX.

Y por último, el eje epidemiológico, que ingresa con una extraordinaria fuerza durante la segunda mitad del siglo XX, concierne la posibilidad de definir a las enfermedades como consecuencia de señales de riesgo, más que como lesiones detectables en el organismo, y donde las enfermedades son definidas por primera vez a partir de parámetros numéricos -por ejemplo, la presión arterial-. Es a partir de un estudio epidemiológico que se trazan las fronteras entre lo normal y lo patológico. Este esquema es el que se dio en llamar el paradigma clínico-epidemiológico o biomédico. A estos cuatro ejes de definición de categorías diagnósticas proponemos agregar un quinto eje que corresponde a las respuestas en términos de políticas de salud. Si bien no sería exactamente un eje similar a los anteriores ya que su naturaleza es de orden diferente, lo incorporamos como un eje transversal con características propias de la dinámica política.

Desde las epidemias de la Peste Negra en Europa del siglo XIV hasta principios del siglo XIX predominó una teoría que intentaba explicar la producción de las enfermedades en la población. Los llamados contagionistas sostenían que la enfermedad se transmitía de una persona enferma a una persona sana ya sea a través del contacto directo entre éstos o a partir de los objetos y pertenencias de los enfermos. Esta explicación de la producción de enfermedades tuvo consecuencias sociales y políticas bastante radicales. Por un lado, se registraba un aumento de la xenofobia en donde determinados grupos eran señalados como los portadores de la enfermedad y el contagio - judíos, "brujas", indígenas, etc. ${ }^{-}{ }^{8}$. Estos grupos eran responsabilizados principalmente cuando se desataba una epidemia ya que ante toda epidemia siempre está latente el peligro de la disolución social. Por otro lado, las acciones políticas apuntaban al aislamiento preventivo o paliativo ya sea de personas, ciudades o puertos. El surgimiento de la cuarentena como uno de los modelos de organización médica occidental vino de la mano de la lepra que implicaba "la expulsión del leproso del espacio común desterrándolo a un lugar confuso donde su enfermedad se mezclaba con la de otros enfermos" ${ }^{\prime}$. La cuarenta fue reemplazada por otro tipo de respuesta que fue instaurada la Peste en el cual el poder de la medicina consistía en la distribución de los indi- 
viduos uno al lado del otro, aislarlos, individualizarlos, vigilarlos dentro de sus propias casas, constatar si están vivos o muertos, llevando un registro diario lo más completo posible de todo lo que acontecía. Es el modelo militar el que suplanta el modelo religioso de purificación de las ciudades.

La teoría contagionista entonces será reemplazada a mediados del siglo XIX por los defensores de la idea de que las poblaciones enfermaban debido a los aires impuros o malsanos (miasmas) que las ciudades emanaban, momento que coincide con el desarrollo del capitalismo industrial en Europa. Así las impurezas presentes en el aire, el agua y el suelo propagaban las enfermedades, aunque con mayor virulencia en la clase obrera debido a las condiciones de miseria y pobreza en la que vivían. Fue la obra pública, a través del saneamiento urbano (cloacas, agua potable, recolección de residuos, de desechos y de cadáveres de animales, mejoras arquitectónicas en las ciudades y viviendas), la política central implementada por los Estados-nación que, junto a las estadísticas vitales, intentaba evidenciar las diferencias en la morbi-mortalidad por regiones en base a la sanidad del ambiente.

Son los descubrimientos de Koch y Pasteur durante la década de 1880 los que produjeron un vuelco radical en la visión de la producción de las enfermedades, generando a su vez una nueva manera de intervenir en la salud pública: "la era de las enfermedades infecciosas" se instala junto con "la era de la salud pública científica". Es ahora el laboratorio el que ejerce una fuerza política legítima sin precedentes ${ }^{10}$. Es el laboratorio con todas sus herramientas científicas el que provee información para la implementación de programas de salud, hospitales para enfermedades agudas -una especie de cuarentena en menor escalay campañas de vacunación cada vez más masivas.

Por último, con la Guerra Fría se instala la noción de riesgo en base a una nueva era de enfermedades prevalentes: las enfermedades crónicas. Es la exposición a determinados factores de riesgo (alimentación no saludable, sedentarismo, tabaco, ingesta excesiva de alcohol, etc.) el que marca la impronta de la época. Las políticas de los Estados se sustentan en esta visión clínico-epidemiológica apuntando a modificar los comportamientos individuales de la población. Como ya ha señalado una prolífera literatura del tema, esta modificación queda librada a las posibilidades económicas, culturales y sociales del individuo $y$, fundamentalmente, a la capacidad de compra de determinados productos conside- rados “saludables". Dentro de esta lógica entonces el acceso a la salud, como cualquier otra mercancía, se consume a través de un acceso diferencial.

A su vez, a la noción de riesgo en el campo clínico-epidemiológico cada vez son más frecuentes las referencias a las nociones de predisposición y susceptibilidad. Este nuevo campo científico ha podido descifrar varias enfermedades propiamente genéticas (cromosómicas y monogénicas) y otras de causalidad multifactorial donde existen genes predisponentes que dependen de factores ambientales o externos para que esas enfermedades se desencadenen ${ }^{11}$. En este campo de conocimiento predomina cierto reduccionismo genético por lo que la mirada sobre el paciente nuevamente se transforma, responsabilizando al paciente por su constitución genética. Sería una propuesta aggiornada del paradigma de los estilos de vida aunque más radical ya que, a diferencia del anterior, ningún individuo puede modificar su constitución genética. La rápida expansión de las investigaciones en el campo de la genética empieza a modificar no sólo las recomendaciones clínicas sino también poco a poca a dar una nueva orientación a la salud pública. Ya están disponibles en el mercado pruebas genéticas que demuestran predisposiciones individuales a ciertas enfermedades. Estas pruebas genéticas son de altísimo costo por lo que genera una profundización de las desigualdades en el acceso a la salud.

\section{Metodología}

El trabajo se centra en dos dimensiones de análisis. Por un lado, en la construcción de las categorías diagnósticas del SUH y de la fibromialgia y, por otro, en las políticas de salud propuestas para intervenir sobre esas enfermedades. La estrategia metodológica es cualitativa sobre la base de fuentes secundarias textuales. Para la primera dimensión, se realizó una selección de la literatura científica nacional e internacional para comprender los diferentes aspectos de la "historia natural" de ambas enfermedades, en función del modelo axial de construcción de categorías diagnósticas. Para la segunda dimensión, se analizaron las propuestas políticas para intervenir sobre esas enfermedades. Concretamente se realizó un análisis del contenido del Programa Nacional del SUH y de un proyecto de ley para la fibromialgia.

Estos dos instrumentos de la política, un enunciado oficial (un programa de salud) y una herramienta legal (un proyecto de ley) constituyen el aspecto formal de la política. Sin embar- 
go, este aspecto formal no implica que la política formal esté distante de un contexto social. Las políticas son fruto de peleas y conflictos de interés y percepciones del mundo. Por lo tanto, los contenidos que se explicitan formalmente en el texto de una política pública también acarrean un saber en disputa y a partir de esos enunciados es posible identificar los conceptos utilizados, las diferentes visiones, la prevalencia de un discurso excluyendo otros y, en este caso particular, visualizar cómo la producción científica impacta en el diseño de las políticas de salud.

El Programa Nacional del SUH de 2015 -hubo una versión en el 2009- se originó bajo el formato de una Unidad de Trabajo Intersectorial (UTI) impulsada por el Ministerio de Salud de la Nación con el argumento de que este formato permitiría un mejor abordaje de la enfermedad entre distintas áreas dentro del ministerio de salud como de las pertenecientes a otros ministerios. Respecto del el proyecto de ley que ingresó en la Cámara de Diputados de la Nación en el 2013 para la fibromialgia fue una iniciativa de un conjunto amplio de pacientes afectadas por esta enfermedad que vienen organizándose en diferentes organizaciones civiles desde 2007.

\section{Resultados y discusión}

\section{Mientras sigan mencionando tu nombre}

Asignar un nombre es el primer paso para definir algo. Una entidad (enfermedad, desorden o síndrome) no sale a la luz completamente hasta que un nombre no sea ideado para ella. Hasta consolidar estos nombres, como los de cualquier otra entidad mórbida, existieron variaciones a lo largo del tiempo. Estas variaciones no sólo se relacionan con nuevos descubrimientos clínicos y biológicos sino que también son afectados por un conjunto de elementos extra-médicos ${ }^{12}$. Algunas enfermedades están estigmatizadas y otras no; algunas son impugnadas en cuanto tal y otras no; algunas son consideradas discapacitantes mientras que otras no; algunas son consideradas relevantes y otras no e incluso existen las llamadas "enfermedades olvidadas" en la agenda de la salud pública internacional. El SUH, como su denominación lo indica, está definido como un Síndrome. Este "primer nombre" tiene algunas dificultades ya que en medicina los síndromes tienen un estatus ambiguo; no son sinónimos de enfermedad aunque, en principio, pueden convertirse en ella. Los "apellidos" refieren a caracte- rísticas específicas de la entidad. Urémico, refiere a la acumulación en la sangre de los productos tóxicos que, en estado normal son eliminados por el riñón, y que se hallan retenidos por un trastorno de su funcionamiento y Hemolítico da cuenta de la destrucción de glóbulos rojos. Este nombre da la idea de cierta objetividad o neutralidad al mismo tiempo que es impronunciable para el público no especializado. Sin embargo, en Argentina se ha convertido en una enfermedad conocida y temida asociada casi exclusivamente al consumo de hamburguesas. Los medios masivos de comunicación la han rebautizado como "el mal de las hamburguesas". Este nombre más popular tuvo consecuencias para las familias con niños: se restringió el consumo de hamburguesas en las casas de comidas rápidas y se lo suplantó por hamburguesas de elaboración casera para asegurar una cocción adecuada - la bacteria no resiste más de $73^{\circ} \mathrm{C}^{13}$.

También la fibromialgia es clasificada como un síndrome. Actualmente es considerada una entidad incluida en el universo de lo que se denominan "síndromes somáticos funcionales" que refiere a diversos síndromes superpuestos que se caracterizan mayormente por diferentes síntomas, sufrimiento y discapacidad. En el universo de los síndromes funcionales también se encuentran otras entidades como el síndrome del intestino irritable, el síndrome de la fatiga crónica, el trastorno de estrés post-traumático y el síndrome de las piernas inquietas. En 1990 adquiere el nombre de fibromialgia, y en 1993 es reconocida por la Organización Mundial de la Salud al ser incluida en la Clasificación Internacional de Enfermedades. Así, la fibromialgia pasó de ser considerada un desorden en donde la persona sentía un dolor localizado o en una región un poco más amplia del cuerpo a un desorden con una multiplicidad de síntomas.

\section{SUH y fibromialgia como categorías diagnósticas}

La construcción de enfermedades siempre se inicia con el reconocimiento de que "algo extraño" está aconteciendo, y a partir de allí una cadena de eventos se va sucediendo donde cada eje (semiológico, morfológico, explicativo y epidemiológico) tiene su momento predominante ${ }^{5}$. El SUH recibió su nombre a mediados de la década de los 50' en una publicación en la que Gasser et al. ${ }^{14}$ lo diferencia de un cuadro con características similares denominado Púrpura Trombocitopénica Trombótica (PTT), creando así una nueva 
entidad mórbida. Posteriormente, los estudios de la patóloga francesa Reneé Habib contribuyeron a entender la histopatología renal del SUH. Las primeras definiciones de esta entidad estuvieron definidas por el eje morfológico. En Argentina se venía observando también este síndrome, se trataba de episodios únicos, no había recurrencias y una vez superada la etapa aguda la mayoría tenía una evolución favorable con baja incidencia de secuelas. El aporte de los médicos argentinos vino de la mano del pediatra Carlos Gianantonio cuando dio a conocer a la Sociedad Argentina de Pediatría un estudio clínico en el que sistematizaba los síntomas de la enfermedad a partir de la recopilación de 58 casos atendidos entre 1957$1963^{15}$ conformando así el primer gestalt semiológico de la enfermedad y liderando el manejo clínico aplicando una nueva técnica terapéutica: la diálisis peritoneal. Durante los 70' las investigaciones se centraron en la nosología de la enfermedad mientras se ensayaban distintas hipótesis sobre su etiología ${ }^{16}$. Un rasgo diferencial fue descrito en la literatura argentina: la enfermedad se presentaba de manera endémica y su incidencia era de 7-10 veces mayor mientras que en el resto de los países ocurrían brotes epidémicos. En esta década es el eje epidemiológico el que reina. La asociación entre la enfermedad y su etiología, una bacteria, será establecida en 1982 cuando un científico estadounidense relaciona la bacteria Escherichia Coli 0157:H7 con dos brotes en Estados Unidos. No obstante, Escherichia Coli ya había sido identificada por el científico dinamarqués Orskov en 1972. En 1985, Karmali et al. ${ }^{17}$ en Canadá, plantearon la hipótesis de que el SUH podía deberse a infecciones por enterobacterias productoras de toxinas y en 1987 describió el aislamiento de una cepa de STEC O157:H7, en una epidemia acotada en un lugar de veraneo a orillas de un lago en Canadá, asociando la enfermedad con esta bacteria que contenía toxinas capaces de generarla. Ese mismo año, J.A. Villar, médico veterinario argentino, publica una antigua investigación de 1977 que había realizado en colaboración con F. Orskov del centro dinamarqués, donde mostraba el aislamiento de este nuevo serotipo del ganado vacuno argentino. Este hallazgo no salió a la luz hasta diez años más tarde. La publicación norteamericana de 1982 animó entonces a los científicos argentinos y dinamarqueses a retomar esa línea de investigación que fue publicada en $1987^{18}$. Es el eje explicativo el dominante durante esos años y en esta breve historia podemos observar una especie de "frente experimental" ${ }^{19}$ a partir de la existencia de un ob- jeto epistémico común, que es manipulado por diversas técnicas, en distintos laboratorios y en diferentes países. Cada laboratorio fue contando una historia o una parte de la misma. Pero no todas esas historias llegan a escribirse completamente, algunas son impugnadas y otras directamente auto-marginalizadas en el propio seno de la actividad científica, como lo fue la historia de Orskov y Villar. A pesar de que la ciencia laboratorial está considerada en el imaginario social como una actividad individual y más bien solitaria, en realidad la investigación científica es netamente colectiva, interdisciplinar y cooperativa delimitado por estructuras no sólo del "estilo de pensamiento" de la comunidad científica propio de una época sino también condicionado por las estructuras tecnológicas e histórico-culturales. En resumen, en este caso observamos cómo a partir de una descripción semiológica, la visualización de lesiones anatómicas evidentes, el reconocimiento de una bacteria, y cómo ésta afecta el funcionamiento normal fisiológico, es que la nueva entidad empieza a adquirir características estables.

Una historia completamente diferente es la de la fibromialgia. Según el estudio de Wolfe y Wali$\mathrm{tt}^{20}$ la fibromialgia cambió su curso muchas veces. El cambio más significativo fue que para que un paciente sea diagnosticado de fibromialgia debía presentar múltiples puntos hipersensibles y un dolor generalizado, a diferencia de su antecesora, la fibrositis, que era descrita por dolor localizado o regional. La fibromialgia se estableció oficialmente por criterios formales en 1990. En esa década la enfermedad ingresa en la "era clínica”. La clasificación de la fibromialgia a partir de una serie de síntomas la instala como cuadro diagnóstico del universo médico. Sin embargo, un importante sector médico fue reticente en la clasificación de esta entidad. Sin ir más lejos, aún hoy la fibromialgia es una entidad impugnada y controvertida, incluso para la práctica clínica. Los estudios científicos que van de 1990 a 2010 empiezan a relacionar a la enfermedad con algunos hallazgos neurobiológicos. Y en 2010 se produce un segundo cambio significativo en la clasificación de la patología. El nuevo criterio excluyó tanto los puntos hipersensibles como el dolor generalizado, remplazándolo por nuevos síntomas como: altos niveles de síntomas somáticos, fatiga, sueño no reparador y problemas cognitivos. En la historia de esta enfermedad el eje semiológico continúa siendo controversial y la búsqueda de lesiones anatómicas es la principal estrategia para catalogar a esta entidad como una enfermedad 
anatomo-patológica y no psicológica. Los estudios neurobiológicos dan cuenta de la necesidad de la medicina de encontrar manifestaciones evidentes como lesiones y causas biológicas. También se está desarrollando cada vez con mayor intensidad una línea de investigación basada en la búsqueda de causas genéticas ${ }^{21,22}$. Pero hasta el momento, esta entidad es tan "escurridiza" que la mirada médica no encuentra rincón corporal donde posar sus ojos ni la mirada anatomo-clínica que revela el espacio tangible del cuerpo ni la mirada tecnológica actual con su parafernalia de aparatos que escanea nuestros cuerpos hasta hacernos casi trasparentes. Por lo que esta entidad que aún carece de un consenso en cuanto a su gestalt semiológico intenta desplegar el resto de los ejes para permanecer dentro del universo médico. En los últimos años es la queja ante el dolor que sienten estos pacientes los que los lleva a la consulta médica. Y es la reumatología, la sub-especialidad médica, que se ha encargado de asistir a estos pacientes incluso ante la ausencia de lesiones o alteraciones orgánicas del sistema músculo-esquelético.

Por lo tanto mientras el SUH despliega con diferentes intensidades los cuatro ejes del diagnóstico de enfermedades desde la década de los $50^{\prime}$ hasta la actualidad, la fibromialgia no termina de generar un consenso ni siquiera al interior del eje semiológico. Si bien desde la década de los 90' se describen una serie de síntomas para detectar la enfermedad, 10 años más tarde ese gestalt semiológico es modificado una vez más. Todavía la fibromialgia no ha adoptado características estables para el raciocinio médico, y en la actualidad están puestos los esfuerzos en detectar lesiones anatómicas visibles o causas genéticas que pueda sostener el andamiaje teórico del paradigma clínico-epidemiológico.

\section{Políticas de salud: la enfermedad maldita vs la enfermedad invisible}

El Programa Nacional contiene dos cambios significativos que modifican la definición "clásica” del SUH. El primero, refiere a la alteración de la edad de los niños que pueden ser afectados por el síndrome. La literatura científica delimitaba la ocurrencia de la enfermedad hasta los 5 años de edad mientras que en el programa se incorpora un umbral etario mayor. El segundo, y que reviste mayor relevancia que el anterior, es la ampliación del universo de bacterias que pueden causar la enfermedad (Shigella dysenteriae tipo 1 y el universo conocido como no-0157). Este segundo cambio tiene una incidencia significativa en el conjunto de las intervenciones prácticas que el programa propone. El eje explicativo, donde reina la fisiopatología en su búsqueda de causas, es el más desarrollado en la propuesta programática.

Toda propuesta política contiene los antecedentes de la temática en cuestión y los argumentos que justifican las acciones prácticas sugeridas. En términos conceptuales el Programa está basado en el modelo de la historia natural de las enfermedades y en los niveles de la medicina preventiva $^{23}$. El documento establece tres líneas de acción: la vigilancia epidemiológica, la educación para la salud y un abordaje integral, que básicamente refiere al manejo clínico de la enfermedad. Sin embargo, a medida que fuimos examinando en detalle el documento y su coherencia lógica de las tres líneas de acción descritas la más fuertemente desarrollada es la que refiere al fortalecimiento de la vigilancia proponiendo unificar la vigilancia epidemiológica con la vigilancia de los alimentos. Es decir, el núcleo fuerte de la propuesta programática es una reorganización interna del sistema del sistema de vigilancia en pos de garantizar la detección temprana e interrupción de la infección por este amplio conjunto de bacterias. A pesar de las cuantiosas críticas que se han realizado al modelo preventivo esta formalización teórica no ha sido reemplazada por nada que la suplante por lo que parece continuar sirviendo de basamento a toda una serie de construcciones en la biomedicina ${ }^{4}$ y podríamos decir que este raciocinio se extiende a la formulación de políticas de salud.

Por lo tanto, es el eje explicativo -que corresponde a la caracterización de la enfermedad como proceso conteniendo causas y una historia natural en donde la medicina se aproxima más a las ciencias "duras" en el domingo de lo biológico- el dominante en la propuesta programática. En definitiva, es la vigilancia epidemiológica la que provee el conocimiento científico tanto espacial, temporal y poblacional junto al "laboratorio" donde se buscan las explicaciones que causan la enfermedad y que da toda una serie de evidencias científicas en las cuales se basará la política de salud.

Ahora veamos cuáles son los problemas que genera una categoría diagnóstica, como la fibromialgia, descrita únicamente por el eje observacional/indiciario. Podríamos afirmar que esta clasificación diagnóstica es la pesadilla para cualquier paciente y para cualquier médico. Al no encontrar una lesión anatómica -recordemos que en la actualidad este eje incluye hasta las le- 
siones moleculares- la enfermedad es impugnada, controvertida o como suele ser tan común actualmente interpretada como la consecuencia de factores psicológicos o psicosociales, o sea, que se la coloca por fuera del universo estrictamente médico. A pesar de los criterios adoptados en 2010, la fibromialgia sigue siendo una enfermedad que ante la mirada médica aparece como una "cosa" que los pacientes "dicen tener". La controversia que subyace es si es un desorden "real”, está sólo en la en la cabeza de los pacientes o es un trastorno psicosomático. Los pacientes que padecen fibromialgia son aquellos que los médicos no quieren atender porque para la mirada médica los límites entre el cuerpo y la mente son bastante difusos. La fibromialgia se encuentra dentro del grupo de enfermedades denominadas síndromes funcionales que poseen muchos síntomas sin agente etiológico. Así como los médicos no quieren atender a este tipo de pacientes, los pacientes no quieren ser clasificados como enfermos psicosomáticos, porque detrás de esta clasificación hay una percepción de que el paciente finge, miente o exagera para escapar de las obligaciones de la vida cotidiana o en el otro extremo es considerado una persona "débil" o "más susceptible" que el resto de los seres humanos, generando pena o fastidio en su entorno. Estas diferentes percepciones, aunque todas negativas, operan fuertemente en el imaginario social y terminan por convertir al paciente de este tipo de trastornos en un "farsante", no solo ante la mirada experta del médico sino también ante su entorno familiar y social.

Lo que ha venido sucediendo en varios países es que los pacientes empezaron a nuclearse en asociaciones civiles para que su padecimiento sea considerado una enfermedad y así construir la tan ansiada legitimidad que da la posibilidad de que la clínica intervenga sobre los cuerpos. Para estos pacientes, la fibromialgia validada científicamente le provee legitimación a sus síntomas y a un diagnostico aceptable ${ }^{24}$. En 2007 en Argentina se conformó una organización civil, FibroAmerica, que nuclea a los pacientes de tres categorías diagnósticas: la fibromialgia, el síndrome de fatiga crónica y la sensibilidad química múltiple. FibroAmérica se constituyó con el objetivo de llevar adelante distintos planes para mejorar la calidad de vida de estos pacientes. Sin embargo, la calidad de vida solo puede alcanzarse si la enfermedad es reconocida como tal. Según la organización fue pionera mundial al legitimar la asociación entre estas tres enfermedades y el concepto de discapacidad y concientizar sobre lo que ellos denominan las "discapacidades invisi- bles", creando por primera vez el término que los define.

En 2013 los pacientes elevaron un proyecto de ley en la Cámara de Diputados (D 6218) cuyo objetivo era que la legislación reconozca a estos tres síndromes como enfermedades y que así se equiparen los derechos de estos pacientes a los de otras enfermedades discapacitantes. El entonces ministro de salud consideraba que no había que hacer una ley para cada enfermedad sino que las enfermedades con baja incidencia debían ser colocadas en un paquete legal común bajo la denominación de enfermedades raras o poco frecuentes. Pero los pacientes y los diputados de la oposición -quienes presentaron este proyecto de ley- encontraban una diferencia sustancial entre las enfermedades raras o poco frecuentes y los síndromes funcionales justamente por el inconveniente de lo oculto, de lo invisible, de lo no demostrable.

\section{Consideraciones finales}

Este estudio de casos en clave comparada demostró que la jerarquía otorgada a cada eje de definición de una categoría diagnóstica tiene una influencia decisiva en la formulación de una propuesta política, como hemos analizado en el Programa Nacional para un caso o en un proyecto de ley para el otro. Este trabajo también reveló las distintas políticas propuestas en la medida en que las construcciones de las categorías diagnósticas fueron sustancialmente diferentes.

En cuanto al SUH, es el "laboratorio", en donde la medicina se aproxima más al dominio de lo biológico, el proveedor de evidencia científica que legitima las intervenciones de la salud pública. Parafraseando a Latour ${ }^{10}$ es la ciencia la que se auto-legitima y crea a su vez una fuerza política irremplazable modificando a la sociedad en su conjunto. En cambio, cuando en una enfermedad como la fibromialgia, ni la medicina ni la biología tienen suficientes "evidencias" científicas para clasificarla de manera definitiva y consensuada, en función de su raciocinio clínico-epidemiológico, las respuestas políticas son otras. La carencia de explicaciones por parte del mundo médico impacta en la vida de los pacientes, en el manejo de su enfermedad y en la propia formulación de políticas de salud. Las oscilaciones entre la búsqueda de lesiones, el reconocimiento de nuevos síntomas y la presunción de causas de origen psicogénicas mantienen a esta entidad en un "limbo". 
Como hemos visto para la fibromialgia $-y$ podríamos extender la idea al conjunto de los síndromes funcionales- es el ámbito político el que intenta legitimarla como una enfermedad ante el fracaso del campo biomédico que no logra vislumbrar su naturaleza biológica al no estar asociada a ninguna anormalidad física. Es entonces un instrumento político -un proyecto de ley- el que defiende su existencia material otor- gando esa legitimidad que necesitan los pacientes para que se desencadenen los mecanismos legales con el objetivo de mejorar la calidad de vida de las personas que sufren este padecimiento. Allí donde el "laboratorio" no pudo dar cuenta de su existencia, es el ámbito político el que ocupa ese lugar. La búsqueda de esa legitimidad entonces se desplaza del ámbito científico al ámbito de los representantes del pueblo.

\section{Colaboradores}

MB Belardo trabajó en la concepción, la investigación y redacción del trabajo. KR Camargo Júnior trabajó en la concepción, orientó en la revisión bibliográfica, en la discusión de los resultados y en la revisión de la redacción final del trabajo. 


\section{Referencias}

1. Rivas M, Miliwebsky E, Chinen I, Deza N, Leotta G. Epidemiología del Síndrome Urémico Hemolítico en Argentina. Diagnóstico del agente etiológico, reservorios y vías de transmisión. Medicina 2006; 66(III):27-32.

2. Repetto H. Síndrome Urémico Hemolítico. Ubicación nosológica actual. Medicina 2006; 66(III):2-5.

3. Fibromialgia. Enciclopedia médica. Washington: Biblioteca Nacional de Medicina; 2016.

4. Camargo Júnior KR. O paradigma clínico-epidemiológico ou biomédico. Revista Brasileira de História da Ciência 2013; 6(2):183-195.

5. Camargo Júnior KR. A construção da AIDS: racionalidade médica e estruturação das doenças. Rio de Janeiro: Universidade do Estado do Rio de Janeiro; 1993.

6. Cardoso MHCA, Camargo KR, Llerena JC. A epistemologia narrativa e o exercício clínico do diagnóstico. Cien Saude Colet 2002; 7(3):555-569.

7. Ribeiro CG, Nogueira MI, Camargo KR. A subjetividade como anomalia: contribuições epistemológicas para a crítica do modelo biomédico. Cien Saude Colet 2006; 11(4):1093-1103.

8. Urquía M. Teorías dominantes y alternativas en epidemiología. Buenos Aires: Universidad Nacional de Lanús; 2006.

9. Foucault M. El nacimiento de la medicina social. Estrategias de poder. Barcelona: Paidós; 1974.

10. Latour B. Give me a laboratory and I will raise the world. In: Biagioli M, editor. The Science Studies Reader. London: Routledge; 1999. p. 141-169.

11. Penchaszadeh V. Genética y derechos humanos. Encuentros y desencuentros. Buenos Aires: Paidos; 2012.

12. Fleck L. Genesis and Development of a Scientific Fact. Chicago: University of Chicago Press; 1981.

13. Belardo MB. Historia politica y social del Síndrome Urémico Hemolítico en la Argentina. Itinerarios de una enfermedad emergente. Buenos Aires: Universidad de Buenos Aires; 2012.

14. Gasser C, Gautier C, Steck A, Siebenmann RE, Oeschslin R. Hämolytich-urámishe syndrome. Bilaterale nierenindennekrosen bei akuten erwobenen hämolytischen anámien. Sechweiz Med Wochenschr 1955; 85:905-909.

15. Gianantonio C, Vitacco M, Mendilaharzu F, Rutty A, Mendilaharzu J. The hemolytic uremic syndrome. J Pediatr 1964; 64:478-491.
16. Gianantonio C, Vitacco M, Mendilaharzu F, Gallo G, Sojo E. The hemolytic-uremic syndrome. Nephron 1973; 11(2):191-194.

17. Karmali M, Petric M, Lim C. The association between idiopathic hemolytic uremic syndrome and infection by verotoxin-producing Escherichia coli. J Infect Dis 1985; 151(5):775-782.

18. Orskov F, Orskov I, Villar J. Cattle as reservoir of verotoxin-producing Escherichia coli O157:H7. Lancet 1987; 2:276.

19. Rheinberger H. Experimental Systems. In: Biagioli M, editor. Historialiy, narration and deconstruction. Routledge: The Science Studies Reader; 1999. p. 417-430.

20. Wolfe F, Walitt B. Culture, science and the changing nature of fibromyalgia. Nat Rev Rheumatol 2013; 9(12):751-755

21. Russell I, Larson A. Neurophysiopathogenesis of fibromyalgia syndrome: a unified hypothesis. Rheum Dis Clin N Am 2009; 35(2):421-435.

22. Spitzer A, Broadman M. A retrospective review of the sleep characteristics in patients with chronic fatigue syndrome and fibromyalgia. Pain Pract 2010; 10(4):294-300.

23. Leavell $\mathrm{H}$, Clark E. Preventive Medicine for the Doctor in his Community. An Epidemiologic Approach. $3^{\text {tr }}$ ed. New York: McGraw-Hill; 1965.

24. Zorzanelli RT. A síndrome da fadiga crônica: apresentação e controvérsias. Psicol estud 2010; 15(1):65-71.

Artigo apresentado em 14/08/2016

Aprovado em 06/10/2016

Versão final apresentada em 08/10/2016 